\section{Pathogenesis of Takotsubo syndrome}

\author{
Daniele Masarone, ${ }^{1}$ Valeria Maddaloni, ${ }^{2}$ \\ Marta Rubino, ${ }^{1}$ Fiorella Fratta, ${ }^{1}$ \\ Annapaola Cirillo, \\ Ludovica Spinelli Barrile, ${ }^{1}$ \\ Roberta Pacileo, ${ }^{1}$ Adelaide Fusco, ${ }^{1}$ \\ Guido Coppola, ${ }^{1}$ \\ Francesca Pisacane, ${ }^{1}$ Paolo Calabrò, ${ }^{1}$ \\ Raffaele Calabrò, ${ }^{1}$ Eduardo Bossone, ${ }^{3-5}$ \\ Maria Giovanna Russo, ${ }^{1}$ \\ Giuseppe Pacileo' \\ 'Department of Cardiology, Monaldi \\ Hospital, Second University of Naples; \\ ${ }^{2}$ Genomic and Cellular Lab, Monaldi \\ Hospital, Second University of Naples; \\ ${ }^{3}$ Heart Department, San Giovanni di Dio \\ e Ruggi d'Aragona University-Hospital, \\ Salerno; ${ }^{4}$ Cardiology Division, Cava de' \\ Tirreni and Amalfi Coast Hospital, Heart \\ Department, University of Salerno, Cava \\ de' Tirreni (SA); ${ }^{5}$ Cardiac Surgery \\ Department, IRCCS Policlinico San \\ Donato, San Donato Milanese (MI), Italy
}

\section{Abstract}

Takotsubo syndrome (TTS) is an enigmatic disease with a multifactorial and still unresolved pathogenesis. Postulated mechanisms include catecholamine excess, coronary artery spasm, and microvascular dysfunction, however catecholamines seem to play a central role in the pathophysiology of TTS. In facts catecholamines have relevant effects on the vasculature and myocardium. Toxic direct effects of catecholamine on myocardium are mediated by multiple pathway including functional hypoxia, metabolic changes and changes in membrane permeability leading to various electrolytic imbalances. Recently report of familial cases has suggested a genetic component. Further research is required to help clarify the proposed hypotheses and to increase our understanding of the cardiovascular responses to acute stress and the pathophysiology underpinning TTS.

There are more things in heaven and earth... than are dreamt of in your philosophy Modified from: Hamlet (1.5.167-8), Hamlet

to Horatio

William Shakespeare

During the past two decades, a novel cardiac syndrome with transient left ventricular systolic dysfunction has been reported. ${ }^{1-2}$

Often referred to as Takotsubo syndrome
(TTS), owing to the shape and appearance of the left ventricle at end systole resembling a Japanese octopus fishing pot during the acute phase, this disorder is also termed stress cardiomyopathy, apical ballooning, and broken heart syndrome. ${ }^{3}$

TTS syndrome is classified as both a primary and an acquired cardiomyopathy by the American Heart Association (AHA), ${ }^{3}$ and as an unclassified cardiomyopathy by the European Society of Cardiology (ESC). ${ }^{4,5}$ Whether this disorder represents a true cardiomyopathy remains to be determined.

In the meantime, according to recent position paper of Heart Failure Association (HFA), ${ }^{6}$ this entity should be clinically labeled as an acute, reversible, heart failure syndrome.

The etiology of TTS remains a subject of investigation.

Observational data in patients with subarachnoid hemorrhage, ${ }^{7}$ reports of its occurrence in patients with pheochromocytoma, and its reproduction by infusion of epinephrine in primates $^{8}$ strongly support the hypothesis that it is caused by excessive adrenergic/catecholamine stimulation. ${ }^{9}$ Alternative hypotheses include myocardial ischemia from multivessel coronary spasm, ${ }^{10}$ transient atherosclerotic plaque rupture ${ }^{11}$ and transient left ventricular outflow tract obstruction. . $^{12,13}$

Moreover, recent report of familial cases has suggested a genetic component. ${ }^{14}$

In this review, we discuss the pathophysiological concepts at the basis of this novel acute heart failure syndrome.

\section{Definition}

Diagnostic criteria for TTS have been proposed from several centers, using various diagnostic definition. ${ }^{6,15,16}$

A detailed description of the diverse definition is behind the scope of this review; however in Table $1^{6,15,16}$ we summarized the diagnostic criteria more frequently used in clinical practice.

\section{Pathophysiology}

The pathophysiology of TTS is complex and reflects the integrated and systemic physiological responses to stress and the cardiovascular responses to sudden surges of catecholamines. ${ }^{17}$

The role of catecholamines seems to be central to the pathophysiology of TTS, and leads to multiple potentially relevant direct and indirect effects on the systemic vasculature, coronary vasculature, and myocardium. ${ }^{18}$

The pathophysiology of TTS can be divided
Correspondence: Daniele Masarone, Department of Cardiology, Monaldi Hospital, AORN dei Colli, Second University of Naples, via L. Bianchi, Naples 80100, Italy.

E-mail: danielemasarone@libero.it

Key words: Takotsubo syndrome; catecholamine induced myocardial toxicity; pathophysiology.

Received for publication: 6 May 2016.

Revision received: 17 January 2017.

Accepted for publication: 18 January 2017.

This work is licensed under a Creative Commons Attribution NonCommercial 4.0 License (CC BYNC 4.0).

CCopyright D. Masarone et al., 2016

Licensee PAGEPress, Italy

Cardiogenetics 2016; 6:5973

doi:10.4081/cardiogenetics.2016.5973

in two phases (Figure 1).

The first starts with increased release of catecholamines, initiated by the activation of the hypothalamic-pituitary-adrenal axis in response to a physical and emotional stress (flight to fight response). ${ }^{19}$

The second phase is the cardiovascular response to surge in circulating catecholamines.

Several hypotheses have been proposed to explain the unique cardiac appearance in TTS and the cardiac response to severe stress. ${ }^{20}$

Many of these hypotheses are still being investigated, as there is no current proven pathophysiological mechanism to explain TTS (Table 2).

\section{Catecholamine-mediated myocardial stunning}

Several features of TTS, including its association with physical or emotional stress, suggest that this disorder may be caused by diffuse catecholamine-induced myocardial stunning. Support for a possible pathogenic role for catecholamines comes from studies in which plasma catecholamines were measured at presentation.

Wittstein et al found that the serum catecholamine concentration was two to three times greater in patients with TTS than that in patients with acute coronary syndrome..$^{21}$

It has been reported that exogenously administered catecholamines, ${ }^{22}$ pheochromocytoma $^{23}$ and acute brain injury ${ }^{24}$ cause similar reversible myocardial dysfunction.

In addition, myocardial biopsies of patients with TTS demonstrate typical features of catecholamine toxicity (accumulation of glycogen 
in cytoplasm of myocytes, disorganization of contractile and cytoskeletal proteins, and an increased extracellular matrix) which nearly complete reversibility at 2 weeks, ${ }^{25}$ and the peculiar distribution of the condition may be explained by the greater adrenergic receptor subtype density at the apex of the heart in comparison with the basal myocardium..$^{26-29}$

Multiple mechanisms have been postulated to explain the cardiotoxicity of catecholamines $^{30}$ (Table 3 ).

The overstimulation of catecholamine receptors enhances cardiac contractility and heart rate, with secondary increase in myocardial oxygen demand that may outweigh oxygen delivery, creating areas of functional hypoxia which can be exacerbated by vasoconstriction in the coronary macro- and micro-circulation and which reduce the supply of high energy phosphates. $^{31}$

The later can be further aggravated by metabolic changes, such as the stimulation of lipolysis with deposition of neutral lipid droplets in cardiomyocytes resulting in an uncoupling of oxidative phosphorylation. ${ }^{32}$

Changes in membrane permeability leading to various electrolytic imbalances, disturb multiple cellular homeostatic processes fostering additional myocardial toxicity. ${ }^{33}$

Finally, Martin and coll. showed decreased reactive hyperemia in response to mental stress in patients with prior TTS $; 4$ these find- ing suggest that vasomotor dysfunction is involved in the pathogenesis of this unique syndrome.

\section{Coronary artery and microvas- cular spasm}

Coronary artery spasm, including epicardial coronary spasm, microvascular spasm, or direct coronary injury, has been suggested as one of the triggering mechanisms of TTS. ${ }^{35,36}$

Ibanez and colleagues suggested a common etiology in TTS syndrome and acute myocar-

Table 1. Diagnostic criteria for Takotsubo syndrome.

\section{Mayo Clinic modified criteria (Prasad, 2008)15}

Transient hypokinesis, dyskinesis, or akinesis of the left ventricular mid segments, with or without apical involvement; the regional wall-motion abnormalities extend beyond a single epicardial vascular distribution, and a stressful trigger is often, but not always, present

New electrocardiographic abnormalities (either ST-segment elevation and/or T-wave inversion) or modest elevation in cardiac troponin level

Absence of obstructive coronary disease or angiographic evidence of acute plaque rupture

Absence of pheochromocytoma or myocarditis

Italian Network criteria (Parodi, 2014) ${ }^{16}$

Typical transient LV wall motion abnormalities extending beyond a single epicardial vascular distribution with complete functional normalization within 6 weeks

Absence of potentially culprit coronary stenosis, or angiographic evidence of acute plaque rupture, dissection, thrombosis or spasm

New and dynamic ST-segment abnormalities or T-wave inversion as well as new onset of transient or permanent left bundle branch block

Mild increase in myocardial injury markers (creatine kinase-MB value $<50 \mathrm{U} / \mathrm{L}$ )

Clinical and/or instrumental exclusion of myocarditis

Post-menopausal woman (optional)

Antecedentstressfulevent (optional)

\section{Heart Failure Association criteria (Lyon, 2016) ${ }^{6}$}

Transient regional wall motion abnormalities of left ventricle or right ventricle, which are frequently, but not always, preceded by a stressful trigger (emotional or physical)

The regional wall motion abnormalities usually extend beyond a single epicardial vascular distribution, and often result in circumferential dysfunction of the ventricular segments involved

The absence of culprit atherosclerotic coronary artery disease including acute plaque rupture, thrombus formation, and coronary dissection or other pathological conditions to explain the pattern of temporary left ventricle dysfunction observed (e.g., hypertrophic cardiomyopathy, viral myocarditis)

New and reversible electrocardiography abnormalities (ST-segment elevation, ST depression, left bundle branch block, T-wave inversion, and/or QTc prolongation) during the acute phase (3 months)

Significantly elevated serum natriuretic peptide (BNP or NT-proBNP) during the acute phase

Positive but relatively small elevation in cardiac troponin measured with a conventional assay (i.e., disparity between the troponin level and the amount of dy functional myocardium present)

Recovery of ventricular systolic function on cardiac imaging at follow-up (3-6 months)

Table 2. Summary of proposed pathophysiological hypothesis and of predisposing factor for Takotsubo syndrome.

Pathophysiological hypothesis

Predisposing factor
Catecholamine-mediated myocardial stunning

Multivessel epicardial coronary artery spasm

Coronary microvascular dysfunction

Left ventricular (LV) outflow tract obstruction and abnormal LV-arterial coupling

Acute atherosclerotic plaque rupture in the left anterior descending coronary artery

Postmenopausal hormonal status

Thrombophilic status

Genetic polymorphism 
dial infarction secondary to left anterior descending artery occlusion, because cardiac ventriculography findings are identical. ${ }^{37}$

The same investigators also documented the presence of plaque rupture on intravascular ultrasonography of the left anterior descending coronary artery of patients with angiographically non obstructive coronary artery disease and a diagnosis of TTS. ${ }^{38}$

However, this mechanism does not entirely explain the extent of regional wall-motion abnormality seen in those without a wraparound left anterior descending coronary artery, the presence of right ventricular dysfunction, and the preservation of apical function that occurs in some patients.

It is therefore unlikely that vasospasm and atherothrombosis of a single artery underlie TTS in most patients.

The possibility of myocardial injury attributable to microvascular spasm has also been suggested. ${ }^{39}$

The characteristics of microvasculature dysfunction after acute psychological stress in patients with TTS include abnormality of endothelium-dependent vasodilation, excessive vasoconstriction, and impairment of myocardial perfusion. ${ }^{40-42}$

According to some reports, increased susceptibility to ergonovine or acetylcholine followed by large vessel spasm, similar to vasospastic angina, may contribute to transient left ventricular (LV) dysfunction. ${ }^{43}$ In addition, using an intracoronary Doppler wire technique, Ako and colleagues demonstrated microcirculatory impairment during transient left ventricular dysfunction. ${ }^{44}$

Transient and reversible coronary microcirculation dysfunction has been also demonstrated using noninvasive transthoracic Doppler echocardiography. ${ }^{45}$

However, because only $30 \%$ of patients showed the characteristics of vasospasm in a challenge test and the histopathological features of endomyocardial biopsy samples taken from patients with TTS show patterns of myocardial abnormalities not associated with infarcted, stunned, or hibernating myocardium, a primary vascular cause for TTS, seems unlikely.

\section{Left ventricular outflow tract obstruction}

Obstruction of the left ventricular outflow tract (LVOT) has been reported in about 10$15 \%$ of patients with TTS (particularly elderly women), associated with increased midseptal thickness, systolic anterior motion of the mitral valve, and mitral regurgitation. ${ }^{46}$

In the presence of increased catecholaminergic tone, this feature could lead to the devel- opment of severe, transient LV midcavity obstruction, mimicking hypertrophic obstructive cardiomyopathy ${ }^{47}$ However, it is likely that LVOT obstruction is a consequence rather than a cause of stress cardiomyopathy, as anteroapical ballooning is extremely rare in other situations where LVOT obstruction is common.

\section{Postmenopausal hormonal status}

The female predominance of TTS has raised the possibility that estrogen may have a role in the pathogenesis of this syndrome.

In a rat model of TTS, Ueyama demonstrated that chronic estrogen supplementation blunted the stress-induced sympathoadrenal outflow from the brain to the heart and upregulated cardioprotective substances such as atrial natriuretic peptide and heat-shock protein 70 , with prevention of stress and catecholamineinduced $\mathrm{LV}$ dysfunction. ${ }^{48}$

Kuo and colleagues proposed that lack of estrogen replacement in the postmenopausal state may predispose women to TTS. ${ }^{49}$

\section{Thrombophilic status}

A whole proteome analysis performed on serum samples was performed on 9 TTS patients, in a comparison with 12 patients with acute coronary syndrome and 13 control patients. Proteomic evaluation revealed differences in fibrinogen g-chain isoforms and fibrin b chains, whose level was increased in TTS

Table 3. Mechanism of catecholamines induced cardiotoxicity.

\begin{tabular}{ll}
\hline Action & Effects \\
Coronary vasoconstriction & Reduced $\mathrm{O}_{2}$ delivery \\
Microvascular spasm & Reduced $\mathrm{O}_{2}$ delivery \\
\hline Increased heart rate & Increased $\mathrm{O}_{2}$ demand \\
Increased contractility & Increased $\mathrm{O}_{2}$ demand \\
\hline Metabolic changes & Reduced ATP production \\
Change membrane permeability & Induction apoptotic pathway \\
\hline
\end{tabular}

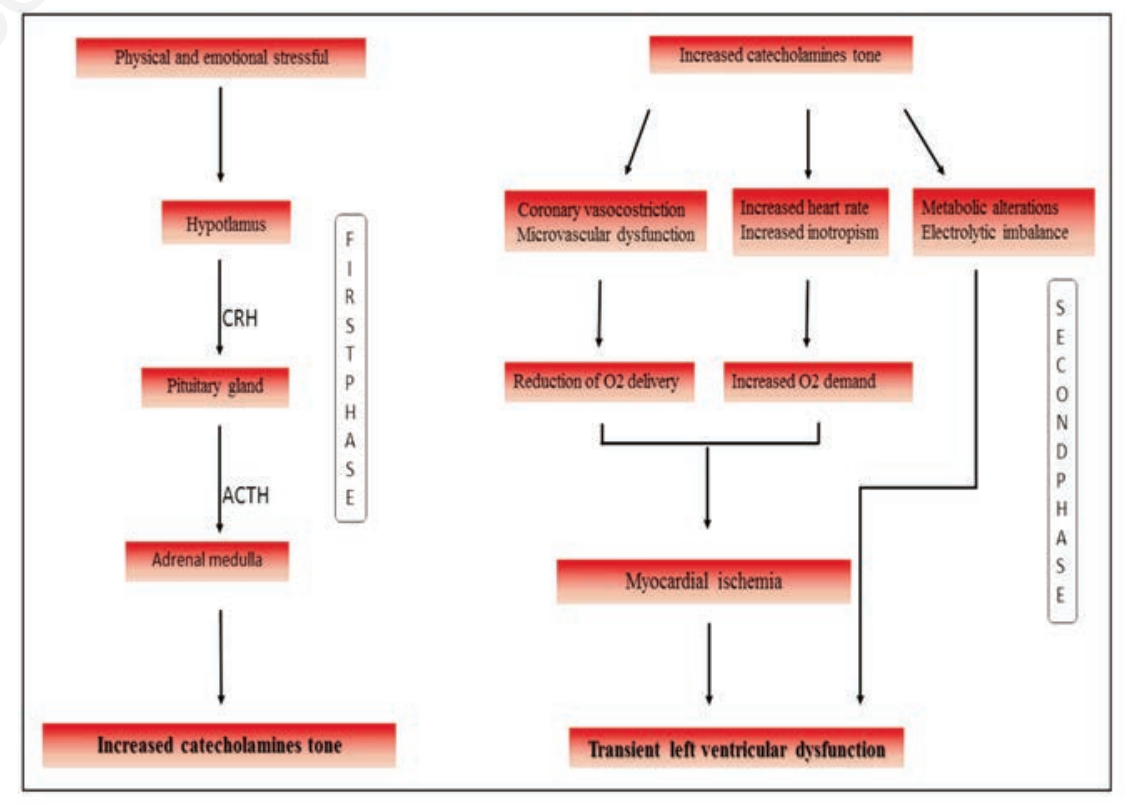

Figure 1. Pathophisiology of Takotsubo syndrome. CRH, corticotropin releasing hormone; ACTH, adreno corticotropic hormone. 
patients compared with acute coronary syndrome patients and controls. Fibrinogen has a key role in fibrin formation and its action is influenced by thrombin, leading to plasma coagulation and platelet aggregation through glycoprotein IIb/IIIa receptors.

The biological activity of fibrinogen isoforms in TTS patients might reflect an activation of the intrinsic clotting cascade..$^{50}$

However, in the recent published TROTA study (ThROmbophylia in TAkotsubo cardiomyopathy $)^{51}$ Cecchi et al. documented that prevalence of thrombophilic disorders in patients with TTS was similar to controls, therefore the role of trombophilic disorder as predisposing factor of this syndrome seems unlikely. ${ }^{52}$

\section{Genetic susceptibility}

The stressful trigger implies that the pathophysiology of TTS has a strong environmental component. However, it is conceivable that some people have a genetic predisposition to stress-induced TTS. Although the syndrome is not considered a primary genetic cardiomyopathy, a number of studies have explored the possibility of genetic risk factors.

A genetic predisposition has been suggested based on the few familial TTS cases described. ${ }^{53,54}$

The genetics of TTS is still vastly unknown, and possible polygenic mechanisms and the strong environmental component make difficult a rapid framing.

In fact, many of the genetic studies conducted so far, but targeted to individual genes, lead to discordant results ${ }^{55}$ and this can be probably because the genetic network of the adrenergic signaling is extremely large.

In 2011 Vriz et al. analyzed the larger population of TTS patients described so far. By analyzing 61 patients and 109 control subjects they found for the first time a strong association between the presence of the malignant homozygous Arg389 polymorphism in the adrenoreceptor 1 and Takotsubo phenotype..$^{56}$

Another polymorphism that has been associated to TTS is L41Q polymorphism of the G protein coupled receptor kinase 5 , in fact Spinelli et coworker found in a cohort of 22 patients with TTS a higher prevalence of the leucine over the glutamine variant at amino acid 41 of GRK5 non catalytic regulatory domain..$^{57}$

Other authors focused their attention on a peculiar aspect of the Takotsubo phenotype. In 2013 Citro et al. focused on impaired endothelium-dependent vasodilation, excessive vasoconstriction and increased sympathetic activation after acute mental stress observed in TTS patients. They analyzed a population of 29 patients and more than 1000 healthy controls for the presence of mutations in the protein Bcl2-associated athanogene 3 (BAG3).

This protein is expressed in only a few cell types, including cardiomyocytes: among its functions, it mediates the cellular response to stress. Sanger sequencing analysis found the presence of $\mathrm{R} 71 \mathrm{Q}$ variation in two patients, one male and one female, and its total absence in large control population. Another variant, P407L, was present in two female patients. The two variants they found may have a role in triggering apoptosis in endothelial cells of coronary vessels and thus in the pathology of TTS. ${ }^{58}$

The first study, not without limitations, that performed a whole-exome sequencing for genes related to catecholamines and adrenergic signaling was carried out on 28 TTS patients including a mother-daughter pair and five recurrent cases. ${ }^{59}$

Authors identified malignant variants in $\mathbf{5 5}$ candidate genes, no homozygous or compound heterozygous and therefore excluded a recessive transmissibility in these patients; among these, 7 genes were common variants in more than one patient in the population analyzed.

About $93 \%$ of the patients had at least a malignant variant, and the finding of the same variants in the control population could be readily accepted by having the basic information of how the environmental influence is decisive in the development of this phenotype. ${ }^{60}$

Given the extremely low power for studies of this size in detecting an effect of a common polymorphism, further studies with high-quality phenotyping, and sharing highnumber/high-quality data in a TTS network will be necessary to estimate the potential role of the genetics as predisposing factor in TTS. $^{61,62}$

\section{Conclusions}

TTS is an enigmatic disease with a multifactorial and a still unresolved pathogenesis.

To explain transient myocardial damage many mechanisms have been proposed, including myocardial dysfunction mediated through catecholamine induced damage, coronary artery spasm or dysfunction, and transient left ventricular outflow tract obstruction. ${ }^{63}$ Therefore, it remains much to learn regarding the underlying pathophysiology of this condition in order to improve diagnostic and treatment pathways. Further research is required to help clarify the hypotheses discussed and to increase our understanding of the cardiovascular responses to acute stress and the pathophysiology underpinning TTS.

\section{References}

1. Sato H, Taiteishi H, Uchida T. Takotsubotype cardiomyopathy due to multivessel spasm. In: Kodama K, Haze K, Hon M, eds. Clinical aspect of myocardial injury: from ischemia to heart failure. Tokyo: Kagakuhyouronsha; 1990. pp 56.

2. Dote K, Sato H, Tateishi $H$, et al. Myocardial stunning due to simultaneous multivessel coronary spasms: a review of 5 cases. J Cardiol 1991;21:203-10.

3. Bybee KA, Kara T, Prasad A, et al. Systematic review: transient left ventricular apical ballooning: a syndrome that mimics ST-segment elevation myocardial infarction. Ann Intern Med 2004;141:85863.

4. Maron BJ, Towbin JA, Thiene G, et al. Contemporary definitions and classification of the cardiomyopathies: An American Heart Association Scientific Statement from the Council on Clinical Cardiology, Heart Failure and Transplantation Committee; Quality of Care and Outcomes Research and Functional Genomics and Translational Biology Interdisciplinary Working Groups; and Council on Epidemiology and Prevention. Circulation 2006;113:1807-16.

5. Elliott P, Andersson B, Arbustini E, et al. Classification of the cardiomyopathies: a position statement from the European Society Of Cardiology Working Group on Myocardial and Pericardial Diseases. Eur Heart J 2008;29:270-88.

6. Lyon AR, Bossone E, Schneider B, et al. Current state of knowledge on Takotsubo syndrome: A Position Statement from the Taskforce on Takotsubo Syndrome of the Heart Failure Association of the European Society of Cardiology. Eur J Heart Fail 2016;18:8-27.

7. Ako J, Sudhir K, Farouque HM, et al. Transient left ventricular dysfunction under severe stress: brain-heart relationship revisited. Am J Med 2006;119:10-7.

8. Paur H, Wright PT, Sikkel MB, et al. High levels of circulating epinephrine trigger apical cardiodepression in a $\beta 2$-adrenergic receptor/Gi-dependent manner: a new model of Takotsubo cardiomyopathy. Circulation 2012;126:697-705.

9. Kassim TA, Clarke DD, Mai VQ, et al. Catecholamine-induced cardiomyopathy. Endocr Pract 2008;14:1137-43.

10. Tsuchihashi K, Ueshima K, Uchida T, et al. Transient left ventricular apical ballooning without coronary artery stenosis: a novel heart syndrome mimicking acute myocardial infarction. Angina Pectoris- 
Myocardial Infarction Investigations in Japan. J Am Coll Cardiol 2001;38:11-7.

11. Prasad A, Dangas G, Srinivasan M, et al. Incidence and angiographic characteristics of patients with apical ballooning syndrome (takotsubo/stress cardiomyopathy) in the HORIZONS-AMI trial: an analysis from a multicenter, international study of ST-elevation myocardial infarction. Catheter Cardiovasc Interv 2014;83:343-7.

12. Ionescu A. Subaortic dynamic obstruction: a contributing factor to haemodynamic instability in tako-tsubo syndrome? Eur J Echocardiogr 2008;9:384-8.

13. Ueyama T. Emotional stress-induced Takotsubo cardiomyopathy: animal model and molecular mechanism. Ann N Y Acad Sci 2004;1018:437-42.

14. Pison L, De Vusser P, Mullens W. Apical ballooning in relatives. Heart 2004;90:6772.

15. Prasad A, Lerman A, Rihal CS. Apical ballooning syndrome (Tako-Tsubo or stress cardiomyopathy): a mimic of acute myocardial infarction. Am Heart J 2008; 155:408-17.

16. Parodi G, Citro, Bellandi B, et al Takotsubo Italian Network (TIN). Revised clinical diagnostic criteria for Tako-tsubo syndrome: the Tako-tsubo Italian Network proposal. Int J Cardiol 2014;172:282-7.

17. Akashi YJ, Nef HM, Lyon AR. Epidemiology and pathophysiology of Takotsubo syndrome. Nat Rev Cardiol. 2015;12:387-9.

18. Lyon AR, Rees PS, Prasad S, et al. Stress (Takotsubo) cardiomyopathy--a novel pathophysiological hypothesis to explain catecholamine-induced acute myocardial stunning. Nat Clin Pract Cardiovasc Med 2008;5:22-8.

19. Arun CP. Fight or flight, forbearance and fortitude: the spectrum of actions of the catecholamines and their cousins. Ann N Y Acad Sci 2004;1018:137-40.

20. Wittstein IS. Stress cardiomyopathy: a syndrome of catecholamine-mediated myocardial stunning. Cell Mol Neurobiol 2012;32:847-57.

21. Wittstein IS, Thiemann DR, Lima JA, et al. Neurohumoral features of myocardial stunning due to sudden emotional stress. NEJM 2005;352:539-48.

22. Abraham J, Mudd J0, Kapur NK, et al. Stress cardiomyopathy after intravenous administration of catecholamines and beta-receptor agonists. J Am Coll Cardiol 2009;53:1320-5.

23. Bravo EL, Tagle R. Pheochromocytoma: state-of-the-art and future prospects. Endocr Rev 2003;24:539-53.

24. Grunsfeld A, Fletcher JJ, Nathan BR. Cardiopulmonary complications of brain injury. Curr Neurol Neurosci Rep 2005;5:488-93.
25. Ueda H, Hosokawa Y, Tsujii U, et al. An autopsy case of left ventricular apical ballooning probably caused by pheochromocytoma with persistent ST-segment elevation. Int J Cardiol 2011;149:50-2.

26. Paur H, Wright PT, Sikkel MB, et al. High levels of circulating epinephrine trigger apical cardiodepression in a beta2-adrenergic receptor/Gi-dependent manner: a new model of Takotsubo cardiomyopathy. Circulation 2012;126:697-706.

27. Meimoun P, Passos P, Benali T, et al. Assessment of left ventricular twist mechanics in Tako-tsubo cardiomyopathy by two-dimensional speckle-tracking echocardiography. Eur J Echocardiogr 2011;12:931-9.

28. Pacileo G, Baldini L, Limongelli G, et al. Prolonged left ventricular twist in cardiomyopathies: a potential link between systolic and diastolic dysfunction. Eur $\mathrm{J}$ Echocardiogr 2011;12:841-9.

29. Kawano H, Okada R, Yano K. Histological study on the distribution of autonomic nerves in the human heart. Heart Vessels 2003;18:32-9.

30. Liaudet L, Calderari B, Pacher P. Pathophysiological mechanisms of catecholamine and cocaine-mediated cardiotoxicity. Heart Fail Rev 2014;1:815-24.

31. Zhang X, Szeto C, Gao E, et al. Cardiotoxic and cardioprotective features of chronic $b$ adrenergic signaling. Circ Res 2008;112:498-509.

32. Behonick GS, Novak MJ, Nealley EW, et al. Toxicology update: the cardiotoxicity of the oxidative stress metabolites of catecholamines (aminochromes). J Appl Toxicol 2001;21:15-22.

33. Borkowski BJ, Cheema Y, Shahbaz AU, et al. Cation dyshomeostasis and cardiomyocyte necrosis: the Fleckenstein hypothesis revisited. Eur Heart J 2001;32:1846-53.

34. Martin EA, Prasad A, Rihal CS, Lerman LO, Lerman A. Endothelial function and vascular response to mental stress are impaired in patients with apical ballooning syndrome. J Am Coll Cardiol 2010;56:1840-6.

35. Delgado GA, Truesdell AG, Kirchner RM, et al. An angiographic and intravascular ultrasound study of the left anterior descending coronary artery in takotsubo cardiomyopathy. Am J Cardiol 2011;108: 888-93.

36. Hoyt J, Lerman A, Lennon RJ, et al. Left anterior descending artery length and coronary atherosclerosis in apical ballooning syndrome (Takotsubo/stress induced cardiomyopathy). Int J Cardiol 2010;145: 112-7.

37. Ibanez B, Navarro F, Farre J, et al. "Takotsubo" transient left ventricular apical ballooning is associated with a left anterior descending coronary with a long course along the apical diaphragmatic surface of the left ventricle. Rev Esp Cardiol 2004:57:209-16.

38. Ibanez B, Navarro F, Cordoba M, et al. Tako-tsubo transient left ventricular apical ballooning: is intravascular ultrasound the key to resolve the enigma? Heart 2005;91:102-8.

39. Vitale C, Rosano GM, Kaski JC. Role of coronary microvascular dysfunction in Takotsubo cardiomyopathy. Circ J 2016;80: 299-305.

40. Kume T, Akasaka T, Kawamoto T, et al. Assessment of coronary microcirculation in patients with takotsubo-like left ventricular dysfunction. Circ J 2005;69:934-93.

41. Abdelmoneim SS, Mankad SV, Bernier M, et al. Microvascular function in Takotsubo cardiomyopathy with contrast echocardiography: prospective evaluation and review of literature. J Am Soc Echocardiogr 2009; 22:1249-55.

42. Galiuto L, De Caterina AR, Porfidia A, et al. Reversible coronary microvascular dysfunction: a common pathogenetic mechanism in Apical Ballooning or Tako-Tsubo Syndrome. Eur Heart J 2010;31:1319-27.

43. Citro R, Pascotto M, Provenza G, et al. Transient left ventricular ballooning (takotsubo cardiomyopathy) soon after intravenous ergonovine injection following caesarean delivery. Int $\mathrm{J}$ Cardiol 2010 21;138:31-4.

44. Ako J, Takenaka K, Uno K, et al. Reversible left ventricular systolicdysfunctionreversibility of coronarymicrovascular abnormality. Jpn Heart J 2001;42:355-63.

45. Citro R, Galderisi M, Maione AG, et al. Sequential transthoracic ultrasound assessment of coronary flow reserve in a patient with tako-tsubo syndrome. J Am Soc Echocardiogr 2006;19:1402-8.

46. El Mahmoud RN, Mansencal N, Pillie're R, et al. Prevalence and characteristics of left ventricular outflow tract obstruction in Tako-Tsubo syndrome. Am Heart J 2008; 156:543-8.

47. Desmet W. Dynamic LV obstruction in apical ballooning syndrome: the chicken or the egg. Eur J Echocardiogr 2006;7:1-4.

48. Ueyama T. Emotional stress-induced Takotsubo cardiomyopathy: animal model and molecular mechanism. Ann N Y Acad Sci 2004;1018:437-44.

49. Kuo BT, Choubey R, Novaro GM. Reduced estrogen in menopause may predispose women to Takotsubo cardiomyopathy. Gend Med 2010;7:71-7.

50. Bang DW, Chung JW, Hyon MS, et al. Proteomic analysis of serum in patients with apical ballooning. Int $\mathrm{J}$ Cardiol 2011;146:118-9.

51. Cecchi E, Parodi G, Fatucchi S, et al. Prevalence of thrombophilic disorders in 
takotsubo patients: the (ThROmbophylia in TAkotsubo cardiomyopathy) TROTA study. Clin Res Cardiol 2016;5:717-20.

52. Golia E, Limongelli G, Natale F et al. Inflammation and cardiovascular disease: from pathogenesis to therapeutic target. Curr Atheroscler Rep 2008;16:1-7.

53. Caretta G, Robba D, Vizzardi E, et al. Takotsubo cardiomyopathy in two sisters: a chance finding or familial predisposition?. Clin Res Cardiol 2015;104:614-6.

54. Limongelli G, D’Alessandro R, Masarone D et al. Takotsubo cardiomyopathy: do the genetics matter?. Heart Fail Clin 2013;9;207-16.

55. Pison L, De Vusser P, Mullens W. Apical ballooning in relatives. Heart 2004;90:12-4.

56. Sharkey SW, Lips DL, Pink VR, et al.
Daughter mother tako-tsubo cardiomyopathy. Am J Cardiol 2013;112:137-8.

57. Spinelli L, Trimarco V, Di Marino S, et al. L41Q polymorphism of the $\mathrm{G}$ protein coupled receptor kinase 5 is associated with left ventricular apical ballooning syndrome. Eur J Heart Fail 2010;12:13-6.

58. Musumeci B, Saponaro A, Pagannone E, et al. Simultaneous takotsubo syndrome in two sisters. Int J Cardiol 2011;165:49-50.

59. Figtree GA, Bagnall RD, Abdulla I, et al. No association of G-protein-coupled receptor kinase 5 or $\beta$-adrenergic receptor polymorphisms with Takotsubo cardiomyopathy in a large Australian cohort. Eur J Heart Fail 2013;15;730-3.

60. Vriz 0, Minisini R, Citro R, et al. Analysis of betal and beta2-adrenergic receptors polymorphism in patients with apical ballooning cardiomyopathy. Acta Cardiol 2011;66:787-90.

61. Citro R, d'Avenia M, De Marco M, et al. Polymorphisms of the antiapoptotic protein bag3 may play a role in the pathogenesis of tako-tsubo cardiomyopathy. Int $\mathrm{J}$ Cardiol 2013;168:1663-5.

62. Goodloe AH, Evans JM, Middha S, et al. Characterizing genetic variation of adrenergic signalling pathways in Takotsubo (stress) cardiomyopathy exomes. Eur J Heart Fail 2014;16:942-9.

63. Bossone E, Lyon A, Citro R, A et al. Takotsubo cardiomyopathy: an integrated multi-imaging approach. Eur Heart J Cardiovasc Imaging 2014;15:366-77. 